\title{
Cateterismo urinário: conhecimento e adesão ao controle de infecção pelos profissionais
} de enfermagem ${ }^{1}$

\section{Urinary catheterism: knowledge and adhesion to the control of infection by the nursing professionals}

\section{Cateterismo urinário: conocimiento y adherencia al control de la infección para los profesionales del oficio de enfermeria}

\author{
Adenícia Custódia Silva e Souza', Anaclara Ferreira Veiga Tipple"', Jackeline Maciel Barbosa"I', Meire \\ da Silva Pereira ${ }^{\mathrm{IV}}$, Regiane Aparecida dos Santos Soares Barreto ${ }^{\vee}$
}

\begin{abstract}
RESUMO
A infecção urinária é freqüente nas internações hospitalares e normalmente estão associadas à instrumentação e manuseio do trato urinário. Objetivamos identificar o conhecimento e a adoção das medidas recomendadas para prevenção e controle de infecção no manuseio e instrumentação do trato urinário associado a cateter vesical pelos profissionais de enfermagem e verificar a existência de rotina escrita e capacitação em serviço. Estudo descritivo, realizado em seis hospitais de ensino do município de Goiânia-GO, no ano de 2003. Os dados foram obtidos mediante entrevistas e 216 horas de observação direta. Participaram 67 profissionais da equipe de enfermagem. Medidas relevantes para o controle de infecção como a higienização das mãos são negligenciadas. Há dicotomia entre o conhecimento e a prática dos auxiliares/técnicos de enfermagem com relação às medidas de prevenção e controle de infecção referente ao manuseio do cateter e sistema de drenagem. A maioria dos enfermeiros conhece e observa as medidas fundamentais para o controle de infecção na execução do cateterismo de demora e de alívio. A capacitação acontece de forma assistemática. A maioria dos serviços possui protocolo com a padronização das técnicas. Há necessidade de um investimento na educação continuada para que medidas eficazes do controle de infecção urinária sejam adotadas.
\end{abstract}

Palavras chave: Cateterismo urinário; Infecção; Cuidados de enfermagem.

\section{ABSTRACT}

The urinary infection is frequent in hospital internment and normally is in association with tract urinary's instrumentation. Our aim is to identify the knowledge and the adoption of the recommended behavior for prevention and control of infection in the handling and instrumentation of the urinary tract associated with the vesical catheter by the nursing professionals and to verify the existence of written routine and qualification in service. A descriptive study was carried through in six educational hospitals in the city of Goiânia-GO - Brazil in 2003. The data were obtained by means of interviews and 216 hours of direct observation, 67 professionals of the nursing team took part in the study. Relevant measures for the infection control, such as the hygienic cleaning of the hands is neglected. There is an uneveness between the knowledge and practice of the assistant/the technician of nursing with regard to the measures of prevention and infection control as for the catheter's caring in the handling and of the draining system. The majority of the nurses knows and observes the basic procedures for the infection control in the execution of the catheterism of delay and relief. The qualification of the nursing professionals happens in a non-sistematic form. The majority

\footnotetext{
1 Pesquisa financiada pelo CNPQ/ vinculada ao Núcleo de Estudos e Pesquisa em Infecção Hospitalar da Faculdade de Enfermagem - UFG.

' Enfermeira. Doutora em Enfermagem. Professora Adjunta da Faculdade de Enfermagem da Universidade Federal de Goiás. Goiânia, Goiás. End: Rua 227, Qd. 68, s/n, Setor Leste Universitário. E.mail: adenícia@fen.ufg.br

"Enfermeira. Doutora em Enfermagem. Professora Adjunta da Faculdade de Enfermagem da Universidade Federal de Goiás. Goiânia, Goiás. E.mail: anaclara@fen.ufg.br

III Enfermeira. Mestranda do Programa de Pós-Graduação da Faculdade de Enfermagem- Mestrado da Faculdade de Enfermagem da Universidade Federal de Goiás. Goiânia, Goiás. E-mail: jackelinemaciel@uol.com.br

IV Enfermeira. Especialista em Saúde Pública. Enfermeira de Centro Cirúrgico do Hospital Geral de Palmas. Palmas, TO. E-mail: meirestar@yahoo.com.br

$\checkmark$ Enfermeira. Mestre em Enfermagem. Professora Assistente da Faculdade de Enfermagem da Universidade Federal de Goiás. Goiânia, Goiás. E-mail:
} remajuau@yahoo.com.br 
of the services, possess protocol with the standardization of the urinary tract manipulation techniques. The data disclose the need of a bigger investment in the continued education so that simple and efficient measurements of the urinary infection control can be adopted.

Key words: Catheterism urinary; Infection; Nursing care.

\section{RESUMEN}

La infección urinaria e frecuente en las internaciones hospitalares y están asociadas a manoseo e instrumentación del tracto urinario. Objetivó identificar al conocimiento y la adopción de las medidas recomendadas para la prevención y control de la infección en el manoseo e instrumentación del tracto urinario, y verificar la existencia de la rutina escrita y la capacitación en servicio. Estudio descriptivo, llevado en seis hospitales de educación de la ciudad de Goiânia-GO- Brazil en 2003. Los datos habían sido conseguidos por medio de entrevistas y de 216 horas del observación directa. 67 profesionales del equipo del oficio

\section{NTRODUÇÃO}

As Infecções do Trato Urinário (ITU) compreendem uma terminologia bastante abrangente, envolvendo ampla variedade de processos e entidades clínicas, acometendo desde o meato uretral ao córtex renal, além de estruturas adjacentes às vias urinárias, como próstata e glândulas uretrais, cujo denominador comum é a invasão de microrganismos em quaisquer desses tecidos. A ITU mantém relevada importância pela sua alta e persistente incidência, representando 35-45\% de todas as infecções hospitalares ${ }^{(1-3)}$. Para diferentes diagnósticos e terapêuticas, por vezes é indispensável o uso de meios invasivos que implicam no manuseio direto ou indireto do trato urinário, por meio de sondagem, irrigação vesical ou procedimentos relacionados. Muito embora o uso de cateteres uretrais tenha trazido grandes benefícios para de enfermeria habían participado del estudio. Los resultados habían demonstrado que excelentes medida para el control de la infección como la limpieza higiénica de las manos están descuidados. Tiene una dicotomía entre el conocimiento y el práctico de la ayudante técnico del cuidado con respecto a las medidas de prevención y de control de la infección cuánto a los cuidados en el manoseo del catéter y del sistema del drenaje. La mayoría de las enfermeras sabe y observa las medidas básicas para el control de la infección en la ejecución del cateterismo de retrasa y relevación. La capacitación de los profesionales del oficio de enfermeria sucede de forma asistemática. La mayoría de los servicios, tienen protocola con la estandardización de las técnicas de la manoseo del tracto urinario. Los datos divulgan la necesidad de un inversión más grande en la educación continuada para adoptar simples y eficientes medida del control de la infección del urinaria.

Palabras clave: Cateterismo del urinario; Infección; Cuidados de enfermería.

inúmeros pacientes, a prática desta cateterização trouxe, também, problemas e riscos potenciais relacionados ao manuseio do trato urinário ${ }^{(4)}$.

Como conseqüência, observa-se alta incidência de ITU, correspondendo 38,5 a $40,0 \%$ de todas as infecções nosocomiais, sendo que 70 a $88 \%$ diretamente relacionadas ao cateterismo vesical, e 5 a $10 \%$ após cistoscopias ou procedimentos cirúrgicos com manuseio no trato urinário ${ }^{(2)}$.

O risco da ITU em decorrência do uso de cateter vesical é diretamente proporcional ao seu tempo de permanência ${ }^{(5)}$. Em um estudo verificou-se a associação entre o tempo de permanência do cateter vesical de demora e o desenvolvimento de infecção do trato urinário, sendo este um importante fator de risco ${ }^{(6)}$. Sabe-se que $1 / 3$ dos dias de sondagem são desnecessários e a remoção precoce, 
Souza ACS, Tipple AFV, Barbosa JM, Pereira MS, Barreto RASS. Cateterismo urinário: conhecimento e adesão ao controle de infecção pelos profissionais de enfermagem. Revista Eletrônica de Enfermagem [serial on line] 2007 Set-Dez; 9(3): 724-735 Available from: URL: http://www.fen.ufg.br/revista/v9/n3/v9n3a12htm

preveniria até $40 \%$ das ITU ${ }^{(1-3)}$. Esse risco depende tanto de fatores predisponentes relacionados ao paciente como: sexo feminino, idade avançada,

diabetes, imunocomprometimento, e fatores externos associados principalmente, a iatrogenia no manuseio, com quebra da assepsia e longo tempo de permanência do cateter ${ }^{(1-3)}$.

Devido à sua alta incidência e significância, medidas preventivas devem ser adotadas com o objetivo de reduzir complicações e custos subseqüentes, uma vez que, as atuais políticas administrativas visam à obtenção da melhor qualidade na assistência com a maior redução dos gastos na prestação dos serviços.

Com a melhoria da qualidade de assistência à saúde, houve um crescimento numérico de pessoas portadoras de doenças de base, graves, em uso prolongado de antimicrobianos. Modificações geradas neste equilíbrio, pela presença de um cateter ou de medicamentos que alteram os mecanismos protetores e selecionam agentes que têm acesso ao uroepitélio, têm contribuído para modificar a etiologia das infecções comunitárias e hospitalares, com aumento de outros agentes gram-negativos e fungos nas ITU nosocomiais (2).

Após o manuseio do trato urinário, como no cateterismo vesical, a complicação mais freqüente é a bacteriúria. Se por um lado, há o benefício do procedimento, por outro existem riscos de complicações decorrentes e aumento dos custos (2).

Dentre todas as infecções hospitalares, a ITU é a mais freqüentemente associada a procedimentos invasivos, entretanto a mais previnível, justificando os esforços para o seu controle.

Os riscos de infecção relacionados aos procedimentos diagnósticos e terapêuticos podem ser minimizados, uma vez que dependem diretamente da capacitação de recursos humanos. Assim, apesar dos avanços e medidas estabelecidas para prevenção e controle das infecções nesta topografia, têm se observado baixa adesão às recomendações, sendo um desafio para as instituições de saúde, devido ao desconhecimento ou à dificuldade em mudar hábitos sedimentados ao longo da vida profissional. Estes fatos parecem indicar a necessidade de um investimento anterior à prática profissional, na formação acadêmica, que tem se mostrado deficiente quanto ao ensino e a prática do controle de infecção ${ }^{(7)}$.

Verificar o conhecimento dos profissionais de saúde que manuseiam e realizam a instrumentação do trato urinário constitui-se etapa diagnóstica, fundamental para a instituição de programas operacionais que contribuam para a adesão às medidas recomendadas para o controle de infecção. Outro aspecto importante a ser considerado é que quando serviços de saúde se constituem campo de prática para a graduação e pósgraduação na área de saúde, tais práticas compõem o processo de formação destes profissionais com muitas chances de ressonância no seu cotidiano ${ }^{(7)}$.

Nesta perspectiva, este estudo analisa nos estabelecimentos de saúde de ensino, quais intercorrências mais comuns estão envolvidas na instrumentação e manuseio do trato urinário e quais medidas estão sendo adotadas por parte dos profissionais 
Souza ACS, Tipple AFV, Barbosa JM, Pereira MS, Barreto RASS. Cateterismo urinário: conhecimento e adesão ao controle de infecção pelos profissionais de enfermagem. Revista Eletrônica de Enfermagem [serial on line] 2007 Set-Dez; 9(3): 724-735 Available from: URL: http://www.fen.ufg.br/revista/v9/n3/v9n3a12htm

responsáveis pela execução desses procedimentos para prevenção e controle das infecções relacionadas ao mesmo.

O estudo teve os seguintes objetivos: identificar o conhecimento e a adoção das medidas recomendadas para prevenção e controle de infecção no manuseio e instrumentação do trato urinário associado a cateter vesical, pelos profissionais de enfermagem e verificar a existência de rotina escrita e capacitação no manuseio e instrumentação do trato urinário.

\section{MÉTODOS}

Pesquisa descritiva realizada no ano de 2003, em seis hospitais de ensino, acima de 100 leitos, do município de Goiânia-GO, após aprovação do Comitê de Ética e Pesquisa Médica Humana e Animal do Hospital das Clínicas da Universidade Federal de Goiás sob o protocolo 051/2002.

Os dados foram obtidos mediante entrevistas dirigidas aos coordenadores de enfermagem, enfermeiros e auxiliares/ técnicos de enfermagem e observação direta a enfermeiros e técnicos /auxiliares de enfermagem que realizavam a técnica de cateterismo vesical e/ou cuidados referentes ao manuseio das sondas. Esses procedimentos foram observados nas Unidades de Terapia Intensiva (UTI), Clinica Cirúrgica e Centro Cirúrgico. Em cada hospital foram realizadas 36 horas de observação direta (12 horas em cada unidade) para a qual se utilizou um check-list para registro. Participaram da pesquisa aqueles que concordaram assinando um Termo de Consentimento Livre e Esclarecido, observando os preceitos éticolegais referentes à pesquisa. Os dados foram dispostos em tabelas e analisados utilizando-se da estatística descritiva.

\section{RESULTADOS E DISCUSSÃO}

Foram entrevistados 29 enfermeiros e 25 técnicos/auxiliares de enfermagem que realizavam a instrumentação e/ou manuseio do trato urinário no seu cotidiano de trabalho, e ainda 13 coordenadores de enfermagem nas respectivas unidades sobre a padronização da técnica de cateterismo vesical e capacitação para instrumentação e manuseio do trato urinário.

Nas 216 horas de observação foram acompanhadas 05 técnicas de Cateterismo Vesical de Demora (CVD) e 03 de Cateterismo Vesical de Alívio (CVA), todas executadas por enfermeiros, e 54 cuidados na manutenção dos cateterismos realizados por auxiliares/técnicos de enfermagem. Como o cateterismo vesical é um procedimento de indicação criteriosa e limitada, houve diferença do número de observações e de entrevistas. Entretanto, todos os profissionais observados na execução dos procedimentos/cuidados foram entrevistados.

Todos os enfermeiros entrevistados (100\%) informaram o uso de técnica asséptica e de pacote específico para a realização do cateterismo vesical, porém dos oito procedimentos observados, 7 (87,5\%), utilizaram pacote específico e 1 (12,5\%) utilizou materiais avulsos estéreis, possibilitando quebra da cadeia asséptica.

Os critérios significantes para o controle de infecção na instrumentação do trato urinário referentes aos procedimentos, cateterismo vesical de demora (CVD) e o cateterismo 
vesical de alívio (CVA), estão dispostos na Tabela 1.

Tabela 1: Distribuição das medidas de controle de infecção citadas pelos enfermeiros e executadas no cateterismo vesical de demora e alívio. Goiânia, 2003.

\begin{tabular}{ccccc}
\hline Medidasde Demo & \multicolumn{2}{c}{ Conhecimento } & \multicolumn{2}{c}{ Execução } \\
& $\mathbf{n = 2 9}$ & $\mathbf{\%}$ & $\mathbf{n = 8}$ & $\%$ \\
\hline Higienização prévia das mãos & 27 & 93,1 & 6 & 75 \\
Higiene íntima prévia & 15 & 51,7 & 5 & 62,5 \\
Uso de luvas esterilizadas & 8 & 27,58 & 8 & 100 \\
Uso de lubrificante hidrossolúvel & 27 & 93,1 & 8 & 100 \\
Realização da anti-sepsia & 14 & 48,27 & 4 & 50 \\
Utilização do campo fenestrado & 26 & 89,65 & 6 & 75 \\
Higienização posterior das mãos & 27 & 93,1 & 8 & 100 \\
Registro do procedimento & 27 & 93,1 & 8 & 100 \\
\hline
\end{tabular}

Quando questionado "em quais momentos você realiza a higienização das mãos", 27 (93,10\%) enfermeiros informaram que a faz antes e após o procedimento, porém dos 8 cateterismos vesicais observados, 6 (75 \%) profissionais higienizaram as mãos antes do procedimento e 8 (100 \%) somente após. Calçar luvas não substitui a necessidade de lavar as mãos, e as mãos devem ser lavadas antes e após o seu uso ${ }^{\left({ }^{8)}\right.}$.

A higienização das mãos surge como a mais simples e mais importante medida na prevenção da infecção nosocomial. Se feita corretamente, remove os microrganismos transitórios adquiridos no contato com os pacientes. É uma conduta de baixo custo e de grande valor para a realidade dos hospitais brasileiros. Deve ser um hábito para os profissionais de saúde, mas sua adesão é um desafio. O uso de luvas esterilizadas e a adoção de rigorosa técnica asséptica devem ser observados sempre na realização de um cateterismo vesical ${ }^{(2,9-10)}$.
Mesmo com a constatação consistente do valor da higienização das mãos na prevenção da transmissão de doenças, profissionais de saúde continuam ignorando o valor de um gesto tão simples e não compreendendo os mecanismos básicos da dinâmica de transmissão das doenças infecciosas ${ }^{(11)}$.

Em 8 (100\%) procedimentos, utilizou-se luva estéril. Em relação ao conhecimento dos 29 profissionais, $8(27,6 \%)$ especificaram a utilização de luva estéril e 21 (72,4\%) citaram o uso de luvas, sem classificá-la como luva de procedimento ou estéril.

Dos 8 procedimentos observados, 5 $(62,5 \%)$ profissionais realizaram a higienização íntima prévia ao cateterismo vesical. Destacase ainda que a metade $15(51,7 \%)$ dos enfermeiros citou este item durante a entrevista, mesmo sendo enfatizado a higiene íntima prévia à anti-sepsia, como medida fundamental na prevenção das ITU associada ao cateter vesical, pois a ação dos anti-sépticos 
Souza ACS, Tipple AFV, Barbosa JM, Pereira MS, Barreto RASS. Cateterismo urinário: conhecimento e adesão ao controle de infecção pelos profissionais de enfermagem. Revista Eletrônica de Enfermagem [serial on line] 2007 Set-Dez; 9(3): 724-735 Available from: URL: http://www.fen.ufg.br/revista/v9/n3/v9n3a12htm

é rapidamente inativada pela presença de matéria orgânica ${ }^{(12-13)}$.

Nos 8 cateterismos vesicais observados foi utilizada solução anti-séptica (PVP-I aquoso), porém a anti-sepsia efetiva aconteceu em apenas $4(50,0 \%)$, com a permanência de 2 minutos desta solução na região genital antes da introdução do cateter e observação dos princípios assépticos: único sentido (anterior para posterior) e fricção (freqüência de três vezes). Entretanto 14 (48,27\%) enfermeiros citaram a realização da anti-sepsia na entrevista e apenas 9 (31\%) informaram a seqüência: meato urinário, pequenos lábios, grandes lábios na mulher e meato urinário, glande, pênis e região pubiana no homem; 5 $(17,2 \%)$ dos enfermeiros realizaram a antisepsia inversa à seqüência acima descrita. Atualmente, a seqüência recomendada para anti-sepsia do cateterismo vesical, tem sido iniciada pelo meato uretral, uma vez que se estabelece a ordem de realização do procedimento pelo local menos contaminado para o de maior contaminação ${ }^{(10,14)}$.

A anti-sepsia é o processo de eliminação ou inibição do crescimento dos microrganismos na pele e mucosas. É realizada com uso de anti-sépticos que são formulações hipoalergênicas e de baixa causticidade, podendo ser classificados em bactericidas ou bacteriostáticos. O preparo da região genital para cateterização vesical deve ser realizado com solução aquosa de iodóforos ${ }^{(9,13)}$. Os iodóforos são combinações de iodo com um agente solubilizante e transportador, a polivinilpirrolidona (PVP), compondo o polivinilpirrolidona-iodo (PVP-I), que atua carregando moléculas de iodo que são liberadas gradualmente em baixas concentrações, mantendo o efeito germicida do iodo, reduzindo sua toxicidade (13). Os iodóforos necessitam de aproximadamente 2 minutos de contato para a liberação do iodo livre, atingindo nível adequado de anti-sepsia, possuem efeito residual de 2 a 4 horas. No entanto, sua ação é rapidamente inativada na presença de matéria orgânica. Podem ser encontrados nas formulações degermante, alcoólica e aquosa ${ }^{(13)}$.

A maioria $27(93,1 \%)$ dos enfermeiros indica o uso de gel lubrificante hidrossolúvel e, na prática, $8(100,0 \%)$ enfermeiros, o utilizaram, porém sem desprezar o primeiro jato, como indicado na ausência de gel lubrificante estéril (10,14-15). Quanto à lubrificação, 7 (24\%) enfermeiros informaram injetar gel na uretra masculina. Há controvérsias entre os autores, entretanto existe alegação empírica que em pacientes maiores de 40 anos, passíveis de hipertrofia prostática, o lubrificante hidrossolúvel reduz o risco de traumatismos e facilita a introdução do cateter ${ }^{(10,16)}$.

A maioria dos profissionais informa e utiliza o campo fenestrado. Sabe-se que o mesmo assegura a assepsia da técnica e o campo fenestrado aberto facilita a sua retirada após a instalação do sistema fechado ${ }^{(2,15)}$.

$O$ registro do procedimento foi citado por $27(93,1 \%)$ dos profissionais e observado em todos os cateterismos. Tal registro e as eventuais intercorrências auxiliam na avaliação acerca da permanência do cateterismo vesical.

Os dados descritos e discutidos a seguir na Tabela 2 referem-se às especificidades na execução do CVD pertinentes para o controle de infecção. 
Souza ACS, Tipple AFV, Barbosa JM, Pereira MS, Barreto RASS. Cateterismo urinário: conhecimento e adesão ao controle de infecção pelos profissionais de enfermagem. Revista Eletrônica de Enfermagem [serial on line] 2007 Set-Dez; 9(3): 724-735 Available from: URL: http://www.fen.ufg.br/revista/v9/n3/v9n3a12htm

Tabela 2: Distribuição das medidas de controle de infecção descritas por enfermeiros e executadas no cateterismo vesical de demora. Goiânia, 2003.

\begin{tabular}{ccccc}
\hline Medidas de Assepsia no Cateterismo Vesical de & \multicolumn{2}{c}{ Conhecimento } & \multicolumn{2}{c}{ Execução } \\
Demora & $\mathbf{n = 2 9}$ & $\mathbf{\%}$ & $\mathbf{n}=\mathbf{5}$ & $\%$ \\
\hline Teste prévio do balonete & 25 & 86,2 & 2 & 40 \\
Conexão prévia da bolsa coletora à sonda de foley & 28 & 96,5 & 5 & 100 \\
Insuflação do balonete & 24 & 82,7 & 5 & 100 \\
Fixação da sonda de foley & 29 & 100 & 3 & 60 \\
Fixação da bolsa coletora inferior à bexiga & 29 & 100 & 5 & 100 \\
\hline
\end{tabular}

A maioria $25(86,2 \%)$ dos enfermeiros descreve o teste do balonete previamente à introdução do cateter durante a entrevista. Constatou-se que este item foi observado por 2 $(40 \%)$ dos enfermeiros na execução do cateterismo vesical de demora. O teste do balonete visa confirmar sua integridade, evitando a saída acidental do cateter, com necessidade de nova cateterização. Ressalta-se a possibilidade de trauma quando o balão é parcialmente preenchido, impedindo a posição ereta do cateter, fazendo com que a ponta do mesmo fique encurvada, possibilitando lesão na mucosa.

O cateter foi conectado à bolsa coletora previamente à sua introdução nos 5 (100\%) dos procedimentos e descrito por $28(96,5)$ enfermeiros. Apesar da ausência de consenso sobre o momento ideal para a conexão da sonda ao tubo coletor considera-se que essa prática facilita a execução da técnica, garante o sistema fechado desde a introdução da sonda e anula a possibilidade de respingo de urina na mucosa ocular (2,9-10,12,15-16).

Todos os profissionais ( $100 \%$ ) referiram a fixação do cateter como medida de prevenção e controle de ITU no CVD e os locais mais citados foram no sexo feminino, região interna da coxa e, no sexo masculino, região inguinal e abdome inferior. No sexo feminino, o recomendado é a fixação na região ânterolateral ou face interna da coxa; no masculino, na região inguinal ou abdominal inferior, para reduzir a curva uretral e eliminar a pressão no ângulo peniano escrotal, o que pode ocasionar fístula ${ }^{(9-10,12,15-16)}$.

Todos os profissionais ( $100 \%$ ) relataram que a bolsa coletora é fixada abaixo do nível da bexiga e acima do chão. Em observação, 5 $(100 \%)$ das bolsas estavam fixadas na grade da cama. A fixação do coletor nas grades favorece a drenagem da diurese e mantém a bolsa coletora abaixo do nível da bexiga e afastada do chão, contudo o sistema necessita ser clampeado pelos profissionais, anteriormente à elevação das grades, prevenindo o refluxo.

Os cuidados na manutenção dos cateterismos vesicais e sistemas de drenagem citados na entrevista pelos técnicos/ auxiliares de enfermagem e observados durante sua execução, estão dispostos na Tabela 3. 
Souza ACS, Tipple AFV, Barbosa JM, Pereira MS, Barreto RASS. Cateterismo urinário: conhecimento e adesão ao controle de infecção pelos profissionais de enfermagem. Revista Eletrônica de Enfermagem [serial on line] 2007 Set-Dez; 9(3): 724-735 Available from: URL: http://www.fen.ufg.br/revista/v9/n3/v9n3a12htm

Tabela 3: Medidas de assepsia descritas e observadas durante os cuidados com a manutenção do sistema fechado de drenagem urinária. Goiânia, 2003.

\begin{tabular}{ccccc}
\hline Medidas de assepsia & \multicolumn{2}{c}{ Conhecimento } & \multicolumn{2}{c}{ Adoção prática } \\
& $\mathbf{n}=\mathbf{2 5}$ & $\mathbf{\%}$ & $\mathbf{n}=\mathbf{5 4}$ & $\mathbf{\%}$ \\
\hline Higienização prévia das mãos & 0 & 0 & 2 & 3,7 \\
Manutenção do sistema fechado & 6 & 24 & 53 & 98,1 \\
Manutenção da bolsa inferior à bexiga & 3 & 12 & 54 & 100 \\
Válvula de drenagem protegida e distante do chão & 7 & 28 & 53 & 98,1 \\
Luvas exclusivas para manusear a bolsa & 12 & 48 & 16 & 29,6 \\
Recipiente limpo e exclusivo para esvaziamento & 4 & 16 & 17 & 31,5 \\
Manutenção da fixação da sonda & 5 & 20 & 34 & 63 \\
Higiene diária do meato uretral & 10 & 40 & 47 & 87 \\
Esvaziamento antes de 2/3 da capacidade da bolsa & 2 & 8 & 44 & 81,5 \\
Higienização das mãos após o manuseio & 1 & 4 & 17 & 31,5 \\
Manutenção do fluxo unidirecional & 6 & 24 & 54 & 100 \\
\hline
\end{tabular}

Os dados mostraram que apenas em 2 $(3,7 \%)$ procedimentos houve a higienização prévia das mãos, e em $17(31,5 \%)$ após o procedimento; a medida foi descrita em apenas uma entrevista, como fundamental após o manuseio do cateter e sistema de drenagem. Assim fica nítida a baixa percepção destes profissionais quanto a este ato tão simples, porém tão eficaz para a prevenção e o controle de infecção urinária como a higienização das mãos.

Com relação ao conhecimento destes profissionais quanto à manutenção do sistema fechado, ao posicionamento da bolsa coletora abaixo do nível da bexiga e proteção da válvula de drenagem, a Tabela 2 mostra descrições nas entrevistas em $6(24 \%), 3(12 \%)$ e 7 $(28 \%)$, respectivamente, e $53(98,1 \%), 54$ $(100 \%)$ e $53(98,1 \%)$, na prática, demonstrando que, apesar de não citarem conhecimento sistematizado desses cuidados na prevenção das ITU, são adotadas como rotina na assistência, confirmando a soberania da cristalização de hábitos sedimentados na prática, embora não estruturados conscientemente na teoria.

Nas entrevistas, o uso de luvas de procedimentos exclusivas para o esvaziamento da bolsa de drenagem foi citado por 12 (48\%) profissionais e o uso de recipiente limpo e exclusivo para desprezar o conteúdo da bolsa por $4(16 \%)$, e observados na técnica por 16 $(29,6 \%)$ e 17 (31,5\%), respectivamente. Entretanto, na maioria das vezes, um único par de luvas de procedimentos e um mesmo recipiente foram utilizados para o esvaziamento da bolsa de drenagem em todos os pacientes de uma mesma enfermaria.

Estudo ${ }^{(17)}$ mostra que a combinação de fatores como a quebra da técnica asséptica, a baixa adesão à higienização das mãos pelos profissionais de saúde na execução desses procedimentos entre pacientes, a contaminação ambiental pelo uso do mesmo recipiente para desprezar a urina da bolsa de drenagem e a diminuição da atenção às medidas de prevenção e controle de infecção 
Souza ACS, Tipple AFV, Barbosa JM, Pereira MS, Barreto RASS. Cateterismo urinário: conhecimento e adesão ao controle de infecção pelos profissionais de enfermagem. Revista Eletrônica de Enfermagem [serial on line] 2007 Set-Dez; 9(3): 724-735 Available from: URL: http://www.fen.ufg.br/revista/v9/n3/v9n3a12htm

contribuíram para o surto de infecção por S. marscescens nos serviço estudado.

Os cuidados na manutenção do cateterismo vesical para prevenção de ITU, incluem manutenção do sistema de drenagem e conecção cateter/ tubo coletor fechados, fluxo descendente contínuo e espontâneo, bolsa coletora abaixo da bexiga e longe do chão, uso de luvas descartáveis e individualizadas, esvaziamento da bolsa com 2/3 da capacidade em recipiente exclusivo descartável ou desinfetado ${ }^{(10,18)}$.

A manutenção da fixação da sonda, a higiene diária do meato urinário e a manutenção do fluxo unidirecional foram medidas descritas nas entrevistas em 5 (20\%), $10(40 \%)$ e $6(24 \%)$, respectivamente, e constatados na técnica em $34(63 \%), 47$ $(87 \%)$ e $54(100 \%)$ das observações.

Vale ressaltar que a prevenção de complicações decorrentes da inserção de um cateter vesical, de um modo geral, está nas mãos da enfermagem e se inicia a partir da decisão pela cateterização, passando pela escolha do cateter, do material e numeração ideais, inserção habilidosa, garantia de uma fixação correta, evitando peso excessivo na bolsa de drenagem e prevenindo a retirada ou tração acidental do mesmo ${ }^{(19-20)}$.

A prática quanto aos cuidados no manuseio do cateter e sistema de drenagem, por parte dos auxiliares/técnicos de enfermagem no estudo, parece não estar fundamentada no conhecimento, mas em rotina estabelecida e supervisionada. Quando acontece o ensino em serviço, os profissionais realizam o cuidado de forma consciente, o resultado se apresenta com melhor qualidade.
A existência de protocolo de padronização de técnicas no manuseio do trato urinário, acessível aos profissionais, foi confirmada por 9 $(69,2 \%)$ dos 13 enfermeiros entrevistados.

As entrevistas mostraram que a capacitação de funcionários admitidos nas unidades para a prevenção e controle das ITU, existe, porém, de maneira assistemática, por meio de discussões de rotinas de acordo com a necessidade individual e escala de trabalho.

É recomendável que se capacite toda equipe profissional quanto à técnica de cateterismo e sua manutenção e que se mantenha educação continuada periódica ${ }^{(12)}$. Além disso, é fundamental elaborar normas e rotinas a fim de padronizar os procedimentos quanto ao material e a técnica utilizada, dando maior segurança ao profissional no desenvolvimento da atividade, a fim de proporcionar melhor assistência ao paciente (12)

Quanto à freqüência de troca do sistema de drenagem, 8 enfermeiros entrevistados $(61.5 \%)$, afirmaram que esta se faz mediante avaliação (por um enfermeiro ou médico) do aspecto da urina, do coletor e presença de resíduos. Dois $(15,4 \%)$ afirmaram que a troca é quinzenal, $1(7,7 \%)$ mediante alteração de exame laboratorial, feito duas vezes por semana e $1(7,7 \%)$ respondeu que as trocas são feitas quando há colabamento da sonda ou vazamento no sistema.

Não há um período pré-estabelecido para a troca do cateter vesical e não se recomenda sua troca em intervalos fixos. O ideal é que se faça uma avaliação constante de sua necessidade, a fim de se detectar sinais que indiquem sua troca, como: formação de resíduos, vigência de sepsis, febre de origem 
Souza ACS, Tipple AFV, Barbosa JM, Pereira MS, Barreto RASS. Cateterismo urinário: conhecimento e adesão ao controle de infecção pelos profissionais de enfermagem. Revista Eletrônica de Enfermagem [serial on line] 2007 Set-Dez; 9(3): 724-735 Available from: URL: http://www.fen.ufg.br/revista/v9/n3/v9n3a12htm

desconhecida, obstrução da luz do cateter ou tubo coletor, suspeita ou evidências de incrustações no lúmen do cateter, contaminação do cateter por técnica inapropriada na instalação ou no manuseio, desconexão acidental do cateter com o tubo coletor, mau funcionamento, deterioração do cateter, tubo ou saco coletor e finalmente piúria visível. É importante lembrar que deve ser trocado todo o sistema, ou seja, cateter, tubo e saco coletor ${ }^{(1-2)}$.

A retirada do cateter vai depender em grande parte das condições do paciente, avaliando criteriosamente sua necessidade pela equipe de saúde que o acompanha. Ocorre muitas vezes a indicação e manutenção imprecisas do cateter vesical, levando a um período maior de cateterização, elevando o risco de ITU.

É sabido que com a remoção precoce do cateter, cerca de $40 \%$ das infecções hospitalares do trato urinário poderiam ser prevenidas $^{(1-2,9)}$.

O grande desafio da prevenção de ITU relacionada ao cateter vesical baseia-se nos cuidados assépticos com o sistema de drenagem, uma vez que a aquisição de ITU está diretamente relacionada à permanência do cateter, por se tratar de um corpo estranho inserido em um meio antes considerado estéril, mantendo uma porta de entrada permanente para microrganismos. Esta contaminação pode ocorrer por via intraluminal, ascendente pela bolsa coletora, constantemente aberta para drenagem, ou via extraluminal, por manter o meato uretral aberto possibilitando contaminação.

Com a evolução no conhecimento das ITU relacionada ao cateter e a sofisticada tecnologia atual, há um grande elenco de medidas proposto para minimizar esses riscos (1).

\section{CONCLUSÃO}

Este estudo evidenciou que a maioria dos enfermeiros conhece e observa as medidas fundamentais para o controle de infecção na execução do cateterismo de demora e de alívio.

Há dicotomia entre o conhecimento e a prática dos auxiliares/técnicos de enfermagem com relação às medidas de prevenção e controle de infecção quanto aos cuidados no manuseio do cateter e sistema de drenagem. A maioria dos entrevistados desconhece estas medidas, entretanto a observação de alguns critérios do controle de infecção na prática parece não estar fundamentada no conhecimento, mas sim na rotina estabelecida e supervisionada.

Contudo, a medida preventiva de maior impacto para a prevenção das ITU no manuseio de cateteres vesicais, a higienização das mãos, não foi evidenciada enquanto conhecimento construído e nem observado na prática de execução desse procedimento, o que coloca em risco a possibilidade de contaminação cruzada, podendo inclusive incorrer em surtos.

Consideramos que a conscientização por meio da integração teoria e prática conferem à equipe de enfermagem maior comprometimento e responsabilidade em executar o cuidado respaldado e fundamentado num conhecimento científico.

A existência e acessibilidade à rotina escrita referente ao cateterismo vesical, foram confirmadas pela maioria dos enfermeiros entrevistados. Destaca-se que a capacitação 
dos profissionais de enfermagem quanto ao manuseio e instrumentação do trato urinário acontece de forma assistemática. Assim é nítida a necessidade da educação continuada para toda a equipe, permitindo constante aprimoramento, atualização e mudança pela percepção dos erros ainda vigentes da prática cotidiana.

O estudo indica os pontos críticos para o controle de ITU no cotidiano da assistência de enfermagem, uma vez que estes foram evidenciados por meio de observação direta da execução dos procedimentos e apresenta impacto importante para o estabelecimento de indicadores a serem observados para a prevenção e o controle das ITU no dia-a-dia das internações hospitalares.

Em relação às ações de enfermagem, pode-se identificar que essas permeiam todos os possíveis atos preventivos para o controle e a prevenção de infecção associada ao cateterismo vesical destacados no estudo. E ainda em face de suas complicações, ressaltamos a importância do papel do enfermeiro frente ao cateterismo vesical no sentido de minimizar ao máximo suas conseqüências, sendo este 0 profissional responsável pela coordenação da equipe de enfermagem, implantação de normas e rotinas ao seu serviço e a otimização do cuidado por meio da implementação da educação em serviço.

A assistência a um paciente com cateter vesical prolongado persiste como problema assistencial. O principio fundamental é observar o conjunto de medidas que sinergicamente contribui para a minimização deste problema. Essas medidas devem ser padronizadas e socializadas a toda equipe.

\section{REFERÊNCI AS}

1. Rodrigues EAC. Infecções do Trato Urinário. In: Rodrigues EAC, Mendonça JS, Amarante JMB, Alves Filho MB, Grimbaum RS, Richtman R. Infecções Hospitalares: Prevenção e Controle. São Paulo (SP): Sarvier; 1997. p.135-148.

2. Gagliardi EDB, Fernandes AT, Cavalcante NJF. I nfecção do Trato Urinário. In: Fernandes AT, Fernandes MOV, Ribeiro Filho, N. Infecção Hospitalar e suas Interfaces na Área de Saúde. São Paulo (SP): Sarvier; 2000. p.459-475.

3. Dantas NM. Infecção do Trato Urinário. In: Oliveira AC, Albuque CP, Rocha LCM. Infecções Hospitalares Abordagem, Prevenção e Controle. Rio de Janeiro (RJ): Medsi; 1998. p.331-43.

4. Nogueira MS, Marvulo MML. Cateterismo Uretral: algumas complicações decorrentes desta prática. Nursing 2001 maio; 36:17-19.

5. Stamm WE. Catheter-associated urinary tract infections. The American Journal of Medicine 1991; 91(3B):65-71.

6. Stamm AMNF, Coutinho MSS. A. Infecção do trato urinário relacionada ao cateter vesical de demora: incidência e fatores de risco. Revista da Associação Médica Brasileira 1999 janeiro; 45(1): 27-33.

7. Tipple AFV, Pereira MS, Hayashida M, Moriya TM, Souza ACS. O ensino do controle de infecção: um ensaio teórico-prático. Rev. Latino-am Enfermagem 2003 março; 11(2): 245-50.

8. Pedrosa TMG, Blom BC. Lavagem das Mãos. In: Pedrosa TMG, Couto RC, Nogueira J.M. Infecção Hospitalar Epidemiologia e Controle. Rio de Janeiro (RJ): Medsi, 1997. p.253-65.

9. Mangini $C$, Manrique AE. Infecção do Trato Urinário Hospitalar Foco em Prevenção. Prática Hospitalar 2000 novembro; (12): 40-43.

10. Hokama CSM, Vattimo MFF. Cateterismo vesical. In: Lacerda RA. Controle de Infecção em Centro Cirúrgico: Fatos, Mitos e Controvérsias. São Paulo (SP): Atheneu; 2003. p. 425-437.

11. Souza ACS, Mendonça AP, Fernandes MSC, Azevedo JMR, Silveira WCR. Lavagem das mãos: adesão dos profissionais de saúde em uma unidade de terapia intensiva neonatal. Acta Scientiarum Health Sciences 2003; 25(2): 14- 153.

12. Pedrosa TMG, Couto RC. Prevenção de Infecção Urinária. In: Pedrosa TMG, Couto RC, Nogueira J M. Infecção Hospitalar Epidemiologia e Controle. Rio de Janeiro (RJ): Medsi; 1997. p.287-92. 
13. Associação Paulista de Estudos e Controle de Infecção Hospitalar (APECIH). Limpeza, desinfecção de artigos e áreas hospitalares e anti-sepsia. São Paulo (SP); 2004.

14 . Mayor ERC, Mendes EMT, OLIVEIRA KR. Manual de Procedimentos e Assistência de Enfermagem. São Paulo (SP): Atheneu; 1999.

15. Stier CJN, Fugmann C, Drehmer ACE, Bragagnolo KL, Martins LTF, Castro MES, et al. Rotinas em Controle de Infecção Hospitalar. Paraná: Netsul; 1995.

16. Posso MBS. Semiologia e Semiotécnica de Enfermagem. São Paulo (SP): Atheneu; 2003.

17. Manning ML, Archibald LK, Bell LM, Banerjee SN, Jarvis WR. Serratia marcescens transmission in a pediatric intensive care unit: a multifactorial occurrence. Am J Infect Control. 2001; 29(2): 115-9.

18. Ayliffe GAJ, Lowbury EJ L, Geddes AM, Williams JD. Controle de Infecçcão Hospitalar. Rio de Janeiro (RJ): Revinter; 1998.

19. Winn, C. Complications with urinary catheters. Professional nurse 1998; 13(5):710.

20. Fiers, S. Indwelling catheters and devices: avoiding the problems. Urologic nursing 1994; 14(3): 141-144.

Artigo recebido em 14.02.07

Aprovado para publicação em 10.12.07 